\title{
Antidiabetic Effect of Ethanolic Extract of Carica papaya Leaves in Alloxan-Induced Diabetic Rats
}

\author{
Augustine I Airaodion ${ }^{1 *}$, Emmanuel 0 Ogbuagu ${ }^{2}$, John A Ekenjoku², Uloaku Ogbuagu ${ }^{1}$ and Victor \\ N Okoroukwu ${ }^{3}$
}

${ }^{1}$ Department of Biochemistry, Federal University of Technology, Nigeria

${ }^{2}$ Department of Pharmacology and Therapeutics, Abia State University, Nigeria

${ }^{3}$ Department of Pharmacology and Therapeutics, Gregory University Uturu, Abia State Nigeria.

*Corresponding author: Augustine Ikhueoya Airaodion, Department of Biochemistry, Federal University of Technology, Owerri, Imo State, Nigeria.

To Cite This Article: Augustine I Airaodion. Antidiabetic Effect of Ethanolic Extract of Carica papaya Leaves in Alloxan-Induced Diabetic Rats. Am J Biomed Sci \& Res. 2019 - 5(3). AJBSR.MS.ID.000917. DOI: 10.34297/AJBSR.2019.05.000917.

Received: 眥 September 13, 2019; Published: 䟧 September 26, 2019

\begin{abstract}
The growing number of diabetes coupled with the harsh side effects of some synthetic drugs has led to the increasing search for alternatives which are relatively cheap with minimal side effects. This study sought to investigate the antidiabetic effect of ethanolic extract of Carica papaya leaves in alloxan-induced diabetic rats. Thirty adult male albino rats were induced intraperitoneally with alloxan. The rats were grouped into six groups of five animals per group: Group A was not induced with alloxan, Group B animals were induced but not treated, Group C animals were treated with glibenclaimide, Group D, E and F animals were treated with 200,400 and $600 \mathrm{mg} / \mathrm{kg}$ body weight of ethanolic leaf extract of C. papaya respectively. The extracts were administered to the animals orally for 14 days. The animal's blood sugar levels were assayed using glucometer. The lipid profiles parameters were assayed using standard methods. The animals administered with 200,400 and $600 \mathrm{mg} / \mathrm{Kg}$ B.W of extract showed significant decrease $(\mathrm{P}<0.05)$ in blood sugar level compared to the untreated animals. The decrease in the blood glucose level of the animals following the administration of the plant extract suggested that the plant extract possesses antidiabetic effects. The extract of C. papaya produces hypolipidaemic effect and this is evident as there are significant decrease in plasma total cholesterol, triglycerides, low density lipoprotein-cholesterol and an increase in plasma high density lipoprotein-cholesterol in the treated groups compared to the untreated group. This implies that $C$. papaya leaves could replace glibenclamide in the treatment of diabetes as it has no side effect. The leaves could also be exceedingly helpful in the control of obesity and hypertension.
\end{abstract}

Keywords: Carica papaya leaves; Fasting Blood Sugar; Lipid Profile; Alloxan-Induced Diabetes.

\section{Introduction}

Carica papaya belongs to the family of Caricaceae, and several species of Caricaceae have been used as remedy against a variety of diseases [1,2]. Originally derived from the southern part of Mexico, C. papaya is a perennial plant, and it is presently distributed over the whole tropical area. In particular, $C$. papaya fruit circulates widely, and it is accepted as food or as a quasi-drug. Many scientific investigations have been conducted to evaluate the biological activities of various parts of C. papaya, including fruits, shoots, leaves, rinds, seeds, roots or latex. The leaves of $C$. papaya have been shown to contain many active components that can increase the total antioxidant power in blood and reduce lipid peroxidation level, such as papain, chymopapain, cystatin, à-tocopherol, ascorbic acid, flavonoids, cyanogenic glucosides and glucosinolates [3] (Figure 1a).

Fruit and seed extracts have pronounced bactericidal activities [5]. Leaves have been poulticed into nervous pains, elephantoid growths and it has been smoked for asthma relief amongst tropical tribal communities. The antiplasmodial potency of ethanolic leaf extract of $C$. papaya against Plasmodium berghei in infected Swiss albino mice has also been reported [4]. Moreover, C. papaya leaf juice is consumed for its purported anti-cancer activity by people living on the Gold Coast of Australia, with some anecdotes of successful cases being reported in various publications. C. papaya leaf extracts have also been used for a long time as an aboriginal remedy for various disorders, including cancer and infectious diseases. $C$. papaya contains two important biologically active compounds viz., chymopapain and papain which are widely used for digestive disorders [6]. It showed that papaya derived papain, caricain, chymopain, and glycerin endopeptidase can improve acidic $\mathrm{pH}$ conditions and pepsin degradation. Other active compounds of $C$. papaya are lipase, a hydrolase, which is tightly bonded to the water-insoluble fraction of crude papain and is thus considered as a "naturally im- 
mobilized" biocatalyst [7]. According to the folk medicine, papaya latex can cure dyspepsia and applicable for external burns and scalds. Seeds and fruits are excellent antihelminthic and antiamoebic [8]. Dried and pulverized leaves are sold for making tea; also, the leaf decoction is administered as a purgative for horses and used for the treatment of genetic-urinary system.

Diabetes is a complex metabolic disorder associated with developing insulin resistance, impaired insulin signaling and $\boldsymbol{\beta}$-cell dysfunction, abnormal glucose and lipid metabolism, sub-clinical inflammation and increased oxidative stress. These metabolic disorders lead to long-term pathogenic conditions including micro- and macro-vascular complications, neuropathy, retinopathy, nephropathy, and a consequent decrease in quality of life and an increase in the rate of mortality [9]. Among the multiple risk factors underlining the incidence and progression of diabetes, diet is the main modifiable factor. Both experimental and epidemiological evidences have shown that consumption of vegetables rich in phenolic compounds and possess high antioxidant capacity may have inverse relationship with the incidence and prevalence of diabetes [10]. Dietary control remains one of the most desirable avenues for the prevention and management of chronic degenerative diseases such as diabetes and cardiovascular diseases. Although various plants have been employed in traditional medicine in Nigeria to treat diabetes, a lot remains to be done scientifically to confirm the efficacy of these herbal drugs. This present study sought to investigate the antidiabetic effect of ethanolic leaf extract of $C$. papaya leaves in alloxan-induced diabetic rats.

\section{Materials and Methods}

\section{Collection and Extraction of Plant Material}

Fresh and health leaves of $C$. papaya free from disease were harvested from the Institute of Agricultural Research and Training, Moor Plantation, Ibadan and were identified by a botanist. They were washed in running water to remove contaminants. They were air dried at room temperature in an open laboratory space for 14 days and milled into powder using an electronic blender (Moulinex). The extraction was done using soxhlet apparatus and ethanol as the solvent according to the method described $[11,12]$. About $25 \mathrm{~g}$ of the powder was packed into the thimble of the soxhlet extractor. $250 \mathrm{~mL}$ of ethanol was added to a round bottom flask, which was attached to the soxhlet extractor and condenser on a heating mantle solvent was heated using the heating mantle and began to evaporate moving through the apparatus to the condenser. The condensate dripped into the reservoir housing the thimble containing the sample. Once the level of the solvent reached the siphon, it poured back into the round bottom flask and the cycle began again. The process could run for a total of 18 hours. Once the process was completed, the ethanol was evaporated in a rotary evaporator at $35{ }^{\circ} \mathrm{C}$ with a yield of $2.98 \mathrm{~g}$ which represents a percentage yield of $11.92 \%$. The extract was preserved in the refrigerator until when needed.

\section{Experimental Animals}

A total of 30 male albino rats with body weight ranging from 160 to $180 \mathrm{~g}$ were obtained from the Federal College of Animal Health and Production Technology, Moor Plantation, Ibadan, Nigeria. They were acclimatized for seven days to Laboratory condition. They were kept in plastic cages and fed with commercial rat chow and supplied with water ad libitum. The rats were used in accordance with NIH Guide for the care and use of laboratory animals; NIPRD Standard Operation Procedures (SOPs). After the acclimatization period, the rats were injected with alloxan monohydrate dissolved in sterile normal saline in a dose of $150 \mathrm{mg} / \mathrm{kg}$ body weight intraperitoneally [13]. After 72 hours of the injection, rats with fasting blood glucose (FBG) at or above $126 \mathrm{mg} / \mathrm{dL}$. (7.0 mmol/L) were considered diabetic.

\section{Grouping of Animals}

The animals were randomly divided into six groups of five animals each. They were grouped as follows:

Group A: $\quad$ Normal control (non-diabetic rats)

Group B: Negative control (diabetic without treatment)

Group C: $\quad$ Positive control (diabetic + Glibenclamide)

Group D: $\quad$ Diabetic $+200 \mathrm{mg} / \mathrm{Kg}$ B. WT of $C$. papaya leaves

Group E: $\quad$ Diabetic $+400 \mathrm{mg} / \mathrm{Kg}$ B. WT of $C$. papaya leaves

Group F: $\quad$ Diabetic $+600 \mathrm{mg} / \mathrm{Kg} \mathrm{B}$. WT of C. papaya leaves

N.B: Glibenclamide is the standard drug use for diabetes management

After fourteen days treatment, the animals were fasted overnight and anaesthetized using diethyl ether. Blood samples were collected by cardiac puncture into heparinized bottles.

\section{Determination of Fasting Blood Sugar}

Fasting blood sugar was determined three times in the course of this study. Firstly, before the induction of diabetes by alloxan secondly, after the induction of diabetes by alloxan administration and lastly, after fourteen (14) days treatment. The blood glucose level were taken by sterilizing the tails of the animals with $10 \%$ alcohol, and cutting the tails using scissors then allowing the blood to touch the test strip which was inserted into a calibrated glucose meter (One touch Glucometer, Acon Laboratory INC. San Diego, USA) according to the methods described [14]. This gave direct reading after 5 seconds in $\mathrm{mg} / \mathrm{dL}$.

\section{Determination of Lipids}

Lipids were extracted and determined according to previously described methods $[15,16]$.

\section{Statistical Analysis}

Data were subjected to analysis of variance using Graph Pad 
Prism. Results were presented as Mean \pm Standard Error of the Mean (SEM). One-way analysis of variance (ANOVA) was used for comparison of the means. Differences between means were significant at $\mathrm{p}<0.05$.

\section{Results and Discussion}

Diabetes is a major health challenge globally and it is on the increase as carbohydrate is the main food consumed by an average human. Up till now, no synthetic drug has been able to provide permanent cure to diabetes. Various in vivo models (e.g., diazoxide, alloxan, or streptozotocin-induced diabetic rats) are used in evaluating medicinal plants with suspected hypoglycemic potentials [17]. In this study, diabetes mellitus was induced using intraperitoneal injection of alloxan at a dose of $140 \mathrm{mg} / \mathrm{kg}$ of body weight. This dose induced diabetes mellitus in the treated rats 72 hours after administration. Alloxan induces diabetes mellitus by selectively destroying the pancreatic beta cells which are involved in the synthesis, storage, and release of insulin which is a peptide hormone that regulate carbohydrate, protein, and lipid metabolism [17].
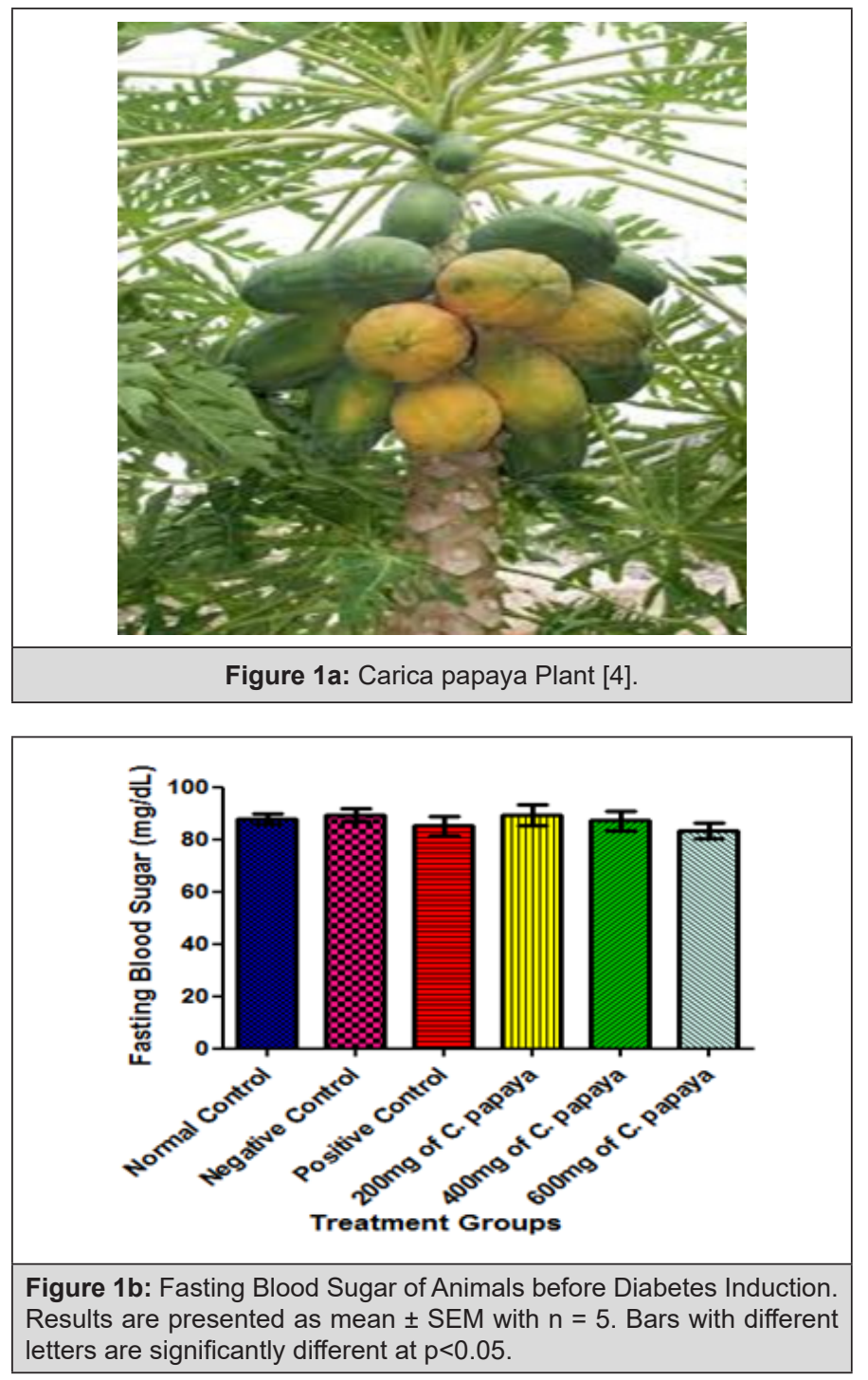

In this study, no significant difference was observed in the fasting blood sugar of all the animals before induction of diabetes (Fig- ure 1b). After the induction of diabetes by alloxan administration, a significant increase was observed in the fasting blood sugar of all the treatment groups when compared with the normal control group at $\mathrm{p}<0.05$ (Figure 2). In the normal control group, the beta cells of the pancreas which produce insulin are intact. But alloxan might have destroyed these beta cells in animals in groups B to F. Alloxan-induced diabetic rats, therefore, no longer have functional pancreatic beta cells and have lost the capacity to secrete insulin which is required for glucose absorption [18].

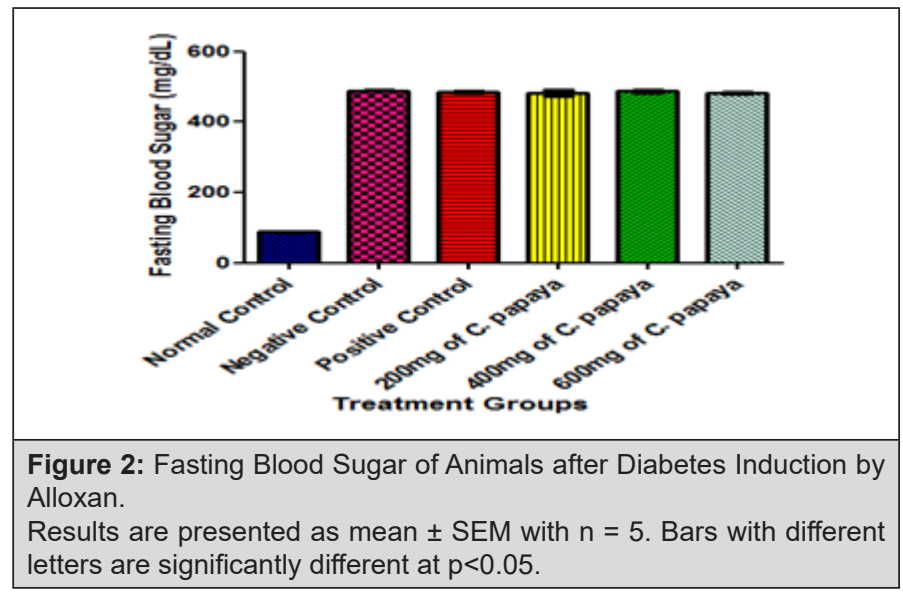

After fourteen days of treatment, animals treated with varying dosages of extract of $C$. papaya leaves had significantly lowered fasting blood sugar when compared with diabetic untreated group (negative control group) as presented (figure 3 ). This suggests that C. papaya leaves may have an extrapancreatic antihyperglycemic mechanism of action. This agrees with the study [14] on the effect of oral intake of African locust bean on fasting blood sugar and lipid profile of albino rats. It also corresponds with another report [19] who studied the effect of methanolic extract of Corchorus olitorius leaves on hypoglycemic and hypolipidaemic activities in albino rats. Several other plants and extracts have also been reported to have an antihyperglycemic and an insulin-stimulatory effect [20-23]. Most of the plants with hypoglycemic properties have been found to contain metabolites such as glycosides, alkaloid and flavonoids [2426]. One interesting finding of this study is that $600 \mathrm{mg} / \mathrm{kg}$ body weight of $C$. papaya leaf extracts reduced blood glucose as much as glibenclamide, the standard drug used in the treatment of diabetes. This is an indication that $600 \mathrm{mg} / \mathrm{kg}$ body weight of $C$. papaya leaf extract will yield similar result as glibenclamide in the management of diabetes. Since glibenclamide is made of chemicals with adverse health effect, it is advisable to use C. papaya to yield the same result with little or no side effect instead of glibenclamide. Similarly, the extract was able to restore the effect of alloxan-induced diabetes as no significant different was observed when the fasting blood sugar of animals treated with $600 \mathrm{mg} / \mathrm{kg}$ body weight of $C$. papaya leaf extract when compared with the undiabetic animals (normal control) after fourteen days treatment at $\mathrm{p}<0.05$.

Nutritional and medicinal investigation of C. papaya leaves has shown that they contain flavonoids, alkaloids, glycoside, and 
phenolic compounds as well as possesses remarkable antioxidant activity [27]. These substances may be responsible for the hypoglycemic effect of $C$. papaya leaves observed in this study. The fasting blood sugar lowering effect of $C$. papaya leaves may also indicate that it possesses antidiabetic agents which could control hyperglycemia. One therapeutic approach for treating early stage of diabetes is to decrease post-prandial hyperglycemia. This is done by retarding the absorption of glucose through the inhibition of the carbohydrate-hydrolyzing enzymes, $\alpha$-amylase and $\alpha$-glucosidase, in the digestive tract. Consequently, inhibitors of these enzymes determine a reduction in the rate of glucose absorption and consequently blunting the post-prandial plasma glucose rise [28]. Based on these findings, it could be suggested that $C$. papaya leaves may inhibit platelet aggregation and promote vasodilatation, exerting an important protective role in the prevention of the development and progression of vascular complications caused by the hyperglycemic state. In fact, studies have shown that polyphenolic compounds present in some plant can inhibit the process of thrombus formation $[29,30]$.

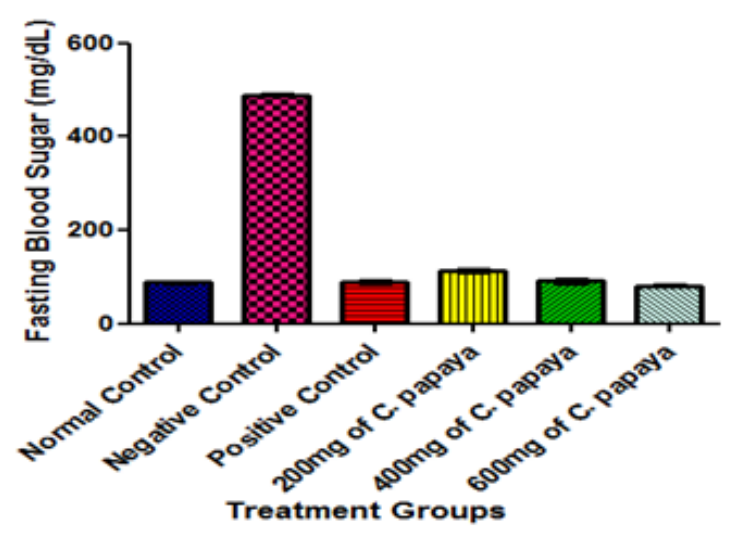

Figure 3: Effect of different Doses of $C$. papaya leaf extract administration on the Fasting Blood Sugar of Animals after 14 Days Treatment.

Results are presented as mean \pm SEM with $n=5$. Bars with different letters are significantly different at $p<0.05$.

Apart from the regulation of carbohydrate metabolism, insulin plays an important role in lipid metabolism. Insulin insufficiency, as in diabetes mellitus, is associated with hypercholesterolemia and hypertriglyceridemia, which have been reported to occur in experimental diabetic rats [31-33]. Hypercholesterolemia could result in a relative molecular ordering of the residual phospholipids, resulting in a decrease in membrane fluidity [34]. Accumulation of triglycerides is one of the leading risk factors in coronary heart disease (CHD). Lipid and lipoprotein abnormalities have been shown to play a major role in the pathogenesis and progression of several disease conditions [35].

In this study, total cholesterol and triglycerides concentrations were observed to decrease significantly when diabetic animals treated with glibenclamide and varying doses of $C$. papaya leaf extract were compared with those of the negative control group (diabetic but untreated animals) at $\mathrm{p}<0.05$ (Figures $4 \& 5$ ). The similar result obtained for glibenclamide and $C$. papaya leaves could mean that $C$. papaya leaves may prevent the progression of CHD. Despite the availability of known anti-diabetic medications, remedies from medicinal plants are used with increasing success to treat this disease and manage its complications better [36]. Furthermore, it has been suggested that plant drugs and herbal formulations are less toxic and are free from side-effects compared with synthetic drugs, leading to an increasing preference for traditional plants over synthetic drugs [37-41]. Increased evidence of therapeutic effectiveness of herbal medicines may have influenced the interest of world health organization (WHO) in hypoglycemic agents of plant origin used in the traditional treatment of diabetes [42]. Hypertriglyceridaemia has been reported in diabetic animals [43]. This was reported to be due to increased absorption and formation of triglycerides in the form of chylomicrons following exogenous consumption of diet rich in fat or through increased endogenous production of triglyceride-enriched hepatic VLDL-cholesterol and decreased triglyceride uptake in peripheral tissues [43]. The effect of $C$. papaya leaves observed in this study might suggest that $C$. papaya leaves can inhibit the absorption and formation of triglycerides in the form of chylomicrons. Hypercholesterolemia has also been reported in diabetic animals [43]. This was attributed to the increased dietary cholesterol absorption from the small intestine following the intake of high fat diet in a diabetic condition [44].

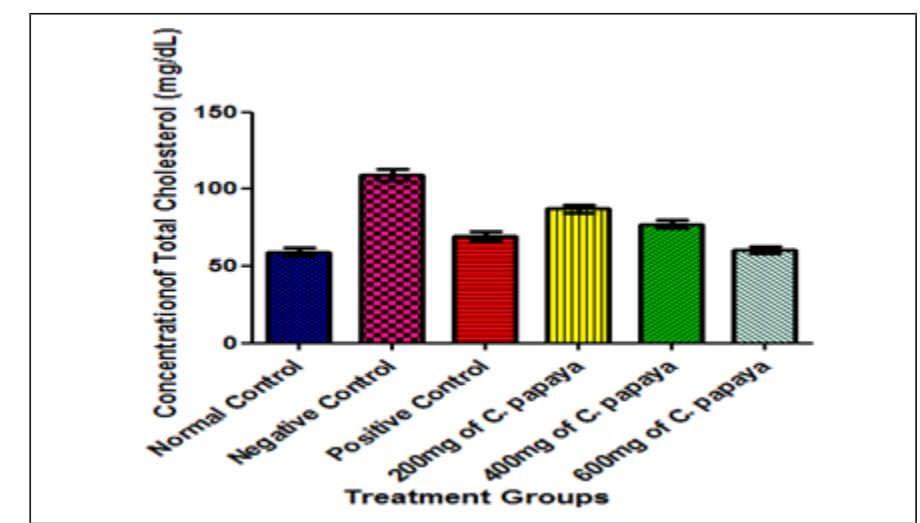

Figure 4: Effect of different Doses of C. papaya leaf extract administration on the Total Cholesterol Concentration of Animals after 14 Days Treatment.

Results are presented as mean \pm SEM with $n=5$. Bars with different letters are significantly different at $p<0.05$.

However, the levels of serum triglyceride, VLDL-cholesterol and total cholesterol were significantly reduced in animals treated with varying doses of extracts of $C$. papaya leaves when compared with those of the negative control group (diabetic but untreated animals) in the present study. Moreover, it can be conjectured that the lipid lowering effects of $C$. papaya leaves could be due to the inhibition of hepatic cholesterol, triglyceride and possibly fatty acid synthesis by the phenolic constituents of C. papaya leaves [27].

Hypertriglyceridaemia has also been reported to be a predictor of hypertension [45]. In the peripheral vascular system, endothelial cells rely on lipoproteins for the transfer of neutral sterols at this site. Although free cholesterol is transferred to HDL-cholesterol 
particles through the functioning of a designated HDL-cholesterol receptor, lecithin cholesterol acyl transferase (LCAT) serves to maintain the concentration toward the HDL core and preserve the hydrophobic nature that facilitates the transfer. Esterification of cholesterol produces cholesterol ester (CE), which is concentrated in HDL core, and may be transferred by cholesterol ester transfer protein (CETP) in the plasma compartment to apo-B containing lipoproteins in exchange for triglyceride. Increased CETP activity would suggest an enrichment of apo-B lipoproteins in plasma, while simultaneously decreasing HDL-cholesterol, and has generally been considered pro-atherogenic [46]. This probably explains why $C$. papaya leaves may lead to a reduction in the risk of developing heart diseases since a high HDL-cholesterol/LDL-cholesterol ratio has been shown to be beneficial and is indicative of a lower risk of cardiovascular diseases [47].

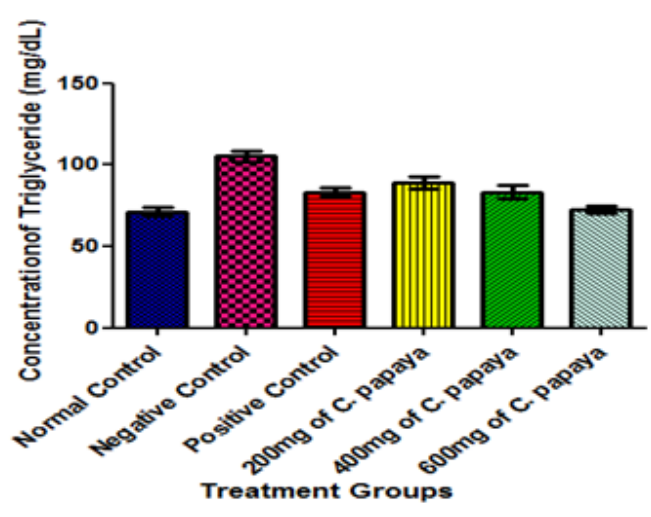

Figure 5: Effect of different Doses of $C$. papaya leaf extract administration on the Triglyceride Concentration of Animals after 14 Days Treatment.

Results are presented as mean \pm SEM with $n=5$. Bars with different letters are significantly different at $p<0.05$.

HDL-cholesterol and LDL-cholesterol are two of the four main groups of plasma lipoproteins that are involved in lipid metabolism and the exchange of cholesterol, cholesterol ester and triglycerides between tissues $[48,49]$. Numerous population studies have shown an inverse correlation between plasma HDL-cholesterol levels and risk of cardiovascular disease, implying that factors associated with HDL-cholesterol protects against atherosclerosis. Some of these factors appear to have antioxidant and anti-inflammatory effects which may obviate processes that initiate atherogenesis $[50,51]$.

Epidemiological studies have also shown that elevated concentrations of total cholesterol and/or LDL-cholesterol in the blood are powerful risk factors for coronary heart disease [52]. Most extra-hepatic tissues, although having a requirement for cholesterol, have low activity of the cholesterol biosynthetic pathway. Their cholesterol requirements are supplied by LDL, which is internalized by receptor-mediated endocytosis. A major function of HDL-cholesterol is to enhance reverse cholesterol transport by scavenging excess cholesterol from peripheral tissues followed by esterification through lecithin: cholesterol acyltransferase and delivering it to the liver and steroidogenic organs for subsequent syn- thesis of bile acids and lipoproteins and eventual elimination from the body [53,54]. This role of HDL-cholesterol has been shown to be responsible for its atheroprotective properties. HDL-cholesterol also regulates the exchange of proteins and lipids between various lipoproteins.
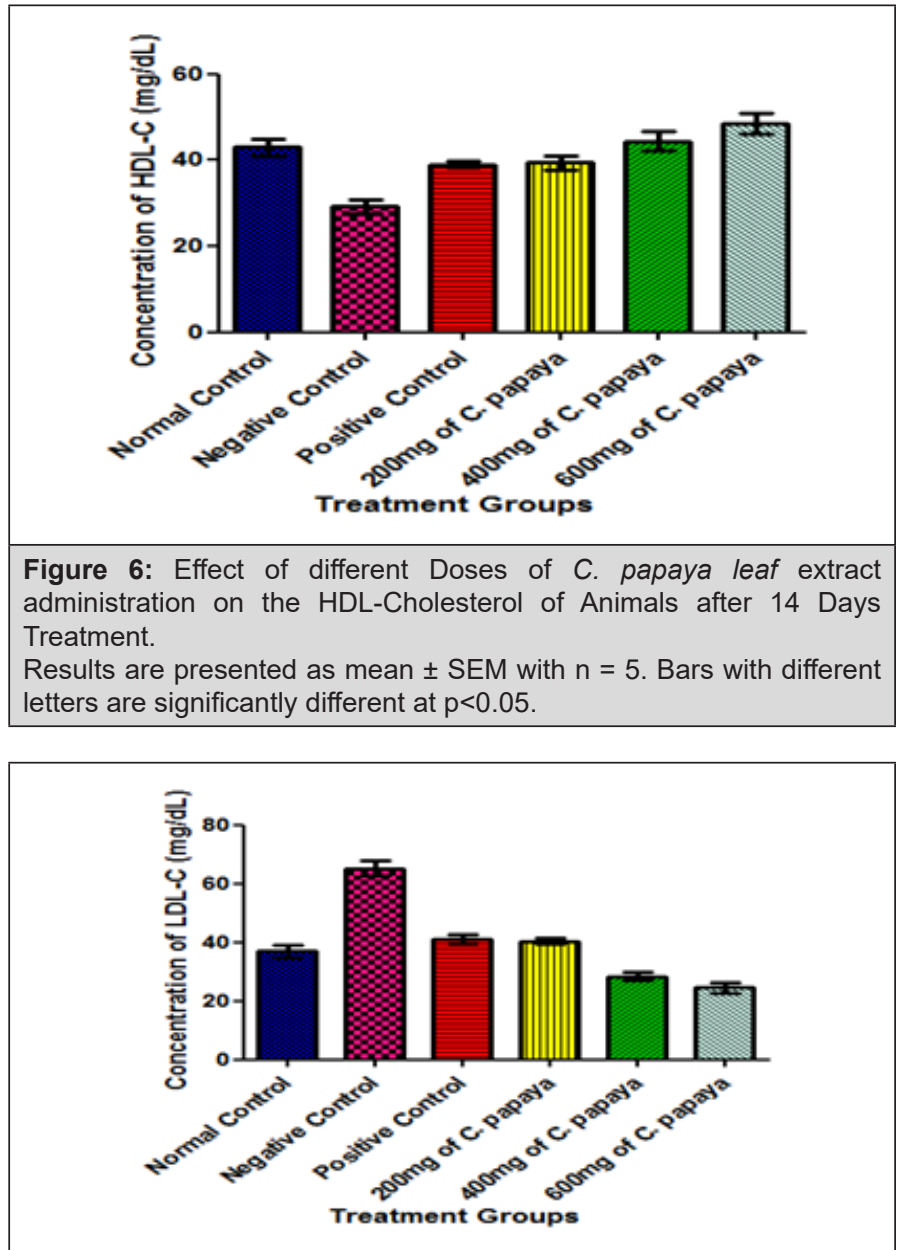

Figure 7: Effect of different Doses of C. papaya leaf extract administration on the LDL-Cholesterol of Animals after 14 Days Treatment.

Results are presented as mean \pm SEM with $n=5$. Bars with different letters are significantly different at $p<0.05$.

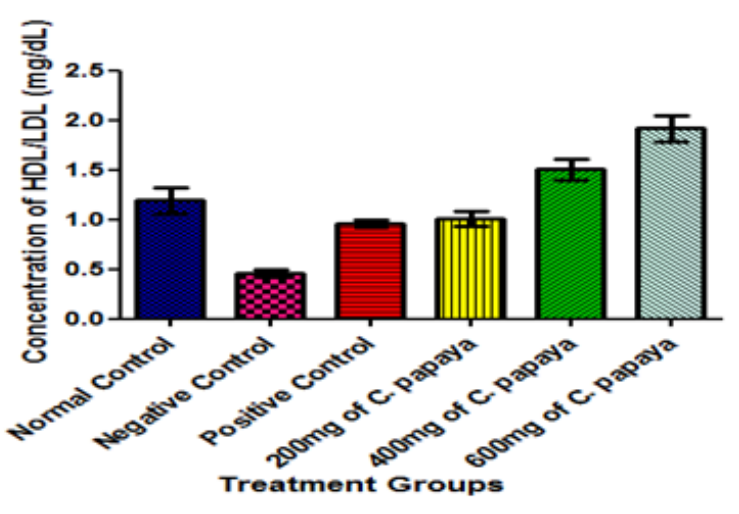

Figure 8: Effect of different Doses of C. papaya leaf extract administration on the HDL/LDL of Animals after 14 Days Treatment. Results are presented as mean \pm SEM with $n=5$. Bars with different letters are significantly different at $p<0.05$ 
In addition, HDL-cholesterol provides the protein components required to activate lipoprotein lipase which releases fatty acids that can be oxidized by the $ß$-oxidation pathway to release energy $[48,49]$. Most importantly, HDL-cholesterol can inhibit oxidation of LDL-cholesterol as well as the atherogenic effects of oxidized LDL-cholesterol by virtue of its antioxidant property [54]. LDL is a lipoprotein that transports cholesterol and triglyceride from the liver to peripheral tissues. It enables fat and cholesterol to move within the water-blood solution of the blood stream. LDL is often called bad cholesterol; hence low levels are beneficial [55].

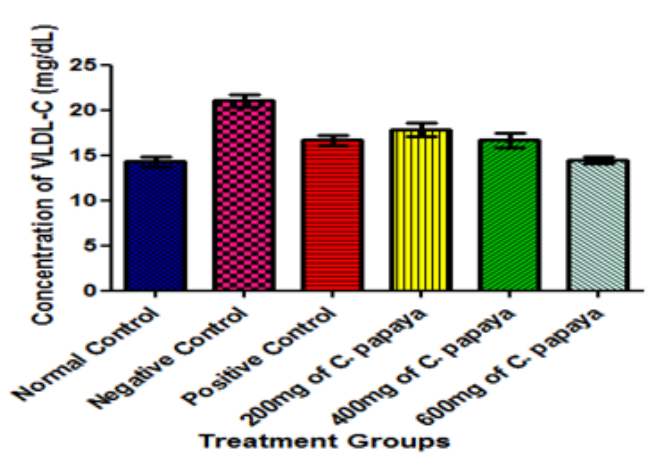

Figure 9: Effect of different Doses of C. papaya leaf extract administration on the VLDL-Cholesterol of Animals after 14 Days Treatment.

Results are presented as mean \pm SEM with $n=5$. Bars with different letters are significantly different at $p<0.05$

Interestingly, the administration of $C$. papaya leaves in varying dosage in this study caused a significant increase in the serum level of HDL-cholesterol when compared with the negative control animals (diabetic but untreated animals) (Figure 6) at $\mathrm{p}<0.05$. HDL-cholesterol is usually referred to as the 'good cholesterol'. Again, $C$. papaya leaves administration significantly decreased the concentration of LDL-cholesterol (bad cholesterol) when compared with that of the negative control group (diabetic but untreated animals) at $p<0.05$ (Figure 7). This result is in agreement with the findings [26] who studied the hypoglycemic and hypolipidaemic activities of methanolic extract of Talinum triangulare leaves in Wistar rats but contradicts another finding who reported a non-significant difference in the LDL-cholesterol concentration when animals were treated with African locust bean for 14 days. The combined effect of increased HDL-cholesterol (good cholesterol) and decreased LDL-cholesterol (bad cholesterol) in the present study resulted in an increased HDL-cholesterol/LDL-cholesterol ratio in animals treated with varying dose of $C$. papaya leaves when compared with the negative control group (Figure 8). This strongly supports the notion that dietary supplementation with the extract of $C$. papa$y a$ leaves may lead to a reduction in the risk of developing heart diseases, because a high HDL-cholesterol/LDL-cholesterol ratio has been shown to be beneficial and is indicative of a lower risk of CHD [56]. Although, the activities of enzymes were not investigated in this study, but it is possible that $C$. papaya leaves decreased the activity of 3-hydroxy-3-methylglutaryl coenzyme A (HMG CoA) reductase (the rate-limiting enzyme in cholesterol biosynthesis). This implies that C. papaya leaves are of significant health importance as far as hyperlipidaemia is concern. It could also be exceedingly helpful in the control of obesity (Figure 9).

\section{Conclusion}

The present study proved that C. papaya leaves is a potent antidiabetic agent with effect like glibenclamide, the standard diabetes drug. It could also reduce the risk of obesity and hypertension due to its hypolipidemic effect.

\section{Conflict of Interest}

Authors declare that no conflict of interest exist in this paper.

\section{Acknowledgement}

Authors wish to acknowledge Mr. Agbaje who took proper care of the animals throughout this study.

\section{References}

1. Munoz V, Sauvain M, Bourdy G, Callapa J, Rojas I, et al. (2000) The search for natural bioactive compounds through a multidisciplinary approach in Bolivia Part II. Antimalarial activity of some plants used by Mosetene indians. J Ethnopharmacol 69(2): 139-155.

2. Mello VJ, Gomes MT, Lemos FO, Delfino JL, Andrade SP, et al. (2008) The gastric ulcer protective and healing role of cysteine proteinases from Carica candamarcensis. Phytomedicine 15(4): 237-244.

3. Seigler DS, Pauli GF, Nahrstedt A, Leen R (2002) Cyanogenic allosides and glucosides from Passiflora edulis and Carica papaya. Phytochemistry 60(8): 873-882.

4. Airaodion AI, OgbuaguEO, Airaodion EO, Ogbuagu U, Ekenjoku JA (2019) Antidiabetic effect of ethanolic extract of Carica papaya leaves in alloxan-induced diabetic rats. International Journal of Bio-Science and Bio-Technology 11(8): 93-109

5. Emeruwa AC (1982) Antibacterial substance from Carica papaya fruit extract. J Nat Prod 45(2): 123-127.

6. Huet J, Looze Y, Bartik K, Raussens V, Wintjens R, et al. (2006) Structural characterization of the papaya cysteine protinases at low $\mathrm{pH}$. Biochem Biophy Res Commun 341(2): 620-626.

7. Dominguez de Maria P, Sinisteraa JB, Tsai SW, Alcantara AR (2006) Biotech Adv 24: 493-499.

8. Okeniyi JA, Ogunlesi TA, Oyelami OA, Adeyemi LA (2007) Effectiveness of dried Carica papaya seeds against human intestinal parasitosis: a pilot study. J Med Food 10(1): 493-499.

9. Santaguida PL, Balion C, Hunt D (2008) Diagnosis, prognosis, and treatment of impaired glucose tolerance and impaired fasting glucose. Evid Rep Technol Assess. 12: 1-11.

10. Bahadoran Z, Golzarand M, Mirmiran P, Saadati N, Azizi F (2013) The association of dietary phytochemical index and cardio-metabolic risk factors inadults: Tehran lipid and glucose study. J Hum Nutr Diet 1: 145153.

11. Airaodion AI, Ogbuagu EO, Airaodion EO, Ekenjoku JA, Ogbuagu U (2019) Pharmacotherapeutic effect of methanolic extract of Telfairia occidentalis leaves on glycemic and lipidemic indexes of alloxan-induced diabetic rats. International Journal of Bio-Science and Bio-Technology 11(8):1-17.

12. Airaodion AI, Ogbuagu EO, Ekenjoku JA, Ogbuagu U, Airaodion EO (2019) Therapeutic effect of methanolic extract of Telfairia occidentalis leaves against acute ethanol-induced oxidative stress in Wistar rats. International Journal of Bio-Science and Bio-Technology 11(7): 179-189.

13. Prince PSM, Menon VP (2001) Antioxidant action of Tinosporacordifolia root extract in alloxan diabetic rats. Phytotherapy Res 15(3): 213-218. 
14. Airaodion AI, Airaodion EO, Ogbuagu EO, Ogbuagu U, Osemwowa EU (2019) Effect of Oral Intake of African Locust Bean on Fasting Blood Sugar and Lipid Profile of Albino Rats. Asian Journal of Research in Biochemistry 4(4): 1-9.

15. Owoade AO, Adetutu A, Airaodion AI, Ogundipe 00 (2018) Toxicological assessment of the methanolic leaf extract of Bridelia ferrugelia. The Journal of Phytopharmacology 7(5): 419-424.

16. Owoade AO, Airaodion AI, Adetutu A, Akinyomi OD (2018) Levofloxacin-induced dyslipidemia in male albino rats. Asian Journal of Pharmacy and Pharmacology 4(5): 620-629.

17. Luka CD, Tijjani H, Joel EB, Ezejiofor UL, Onwukike P (2013) Hypoglycaemic Properties of Aqueous Extracts of Anacardium occidentale, Moringa oleifera, Vernonia amygdalina and Helianthus annuus: A Comparative Study on Some Biochemical Parameters in Diabetic Rats. International Journal of Pharmaceutical Science Invention ISSN (Online): 2319-6718.

18. Meigs JB, Muller DC, Nathan DN, Blake DR, Andres R (2003) The natural history of progression from normal glucose tolerance to type 2 diabetes in the Baltimore longitudinal study of Aging. Diabetes 52(6): 1475-1484.

19. Airaodion AI, Akinmolayan JD, Ogbuagu EO, Airaodion EO, Ogbuagu U, et al. (2019) Effect of methanolic extract of Corchorus olitorius Leaves on hypoglycemic and hypolipidaemic activities in albino rats. Asian Plant Research Journal 2(7): 1-13.

20. Prince PS, Menon PV, Pari L (1998) Hypoglycaemic activity of Syzigium cumini seeds: Effect on lipid peroxidation in alloxan diabetic rats. J Enthopharmacol 61(1): 1-7.

21. Venkateswaran S, Pari L, Saravenan G (2002) Effect of Phaseolus vulgaris on circulatory antioxidants and lipids in streptozotocin induced diabetic rats. J Med Food 5(2): 97-103.

22. Loew S, Kaszkin M (2002) Approaching the problem of bioequivalence of herbal medicinal products. Phytother Res 16(8): 705-711.

23. Airaodion AI, Ogbuagu EO, Airaodion EO, Ekenjoku JA, Ogbuagu U (2019) Pharmacotherapeutic Effect of Methanolic Extract of Telfairia occidentalis Leaves on Glycemic and Lipidemic Indexes of Alloxan-Induced Diabetic Rats. International Journal of Bio-Science and Bio-Technology 11(8): 1-17.

24. Airaodion AI, Olatoyinbo PO, Ogbuagu U, Ogbuagu EO, Akinmolayan JD, et al. (2019) Comparative assessment of phytochemical content and antioxidant potential of Azadirachta indica and Parquetina nigrescens leaves. Asian Plant Research Journal 2(3): 1-14.

25. Airaodion AI, Ibrahim AH, Ogbuagu U, Ogbuagu EO, Awosanya 00, et al (2019) Evaluation of Phytochemical Content and Antioxidant Potential of Ocimum gratissimum and C. papaya Leaves. Asian Journal of Research in Medical and Pharmaceutical Sciences 7(1): 1-11.

26. Airaodion AI, Adeniji AR, Ogbuagu EO, Ogbuagu U, Agunbiade AP (2019) Hypoglycemic and hypolipidaemic activities of methanolic extract of Talinum triangulare leaves in Wistar rats. International Journal of Bio-Science and Bio-Technology 11(5): 1-13.

27. Pinnamaneni R (2017) Nutritional and Medicinal Value of Papaya (Carica papaya Linn) World Journal of Pharmacy and Pharmaceutical Sciences 6(8): 2559-2578.

28. Chen X, Zheng Y, Shen Y (2006) Voglibose BAO, One of the most important $\alpha$-glucosidase inhibitors. Curr Med Chem 13(1): 109-116.

29. Dohadwala MM, Vita JA (2009) Grapes and cardiovascular disease. J Nutr 139(9): 1788-1793.

30. Gresele P, Cerletti C, Guglielmini G, Pignatelli P, de Gaetano G, Violi F (2011) Effects of resveratrol and other wine polyphenols on vascular function: An update. Journal of Nutritional Biochemistry 22(3): 201-211.

31. Loci AS, Shaabha M, Khazraji AL, Husain A, Twaija A (1994) Hypoglycemic effect of a valuable extract on some blood parameters in diabetic animals. J Ethnopharmacol 43(3): 167-171.
32. Ahardh CD, Bjorgell P, Nilson EP (1999) The effect of tolnetamide in lipoproteins and lipoprotein lipase and hormone sensitive lipase. Diabetes Res Clin Pract 46(2): 99-108.

33. Frayn KN (1993) Insulin resistance and lipid metabolism. Curr Opin Lipidol 4: 197-204.

34. Bopanna KN, Kannan J, Suchma G, Balaraman R, Ranthod SP (1997) Antidiabetic and antihyperlipidemic effect of neem seed, kernel powder on alloxan diabetic rabbits. Ind J Pharmacol 29: 162-167.

35. Rotimi OS, David AO, Olusola AT, Regina NU, Elizabeth AB, et al. (2015) Amoxillinand pefloxacin-induced cholesterogenesis and phospholipidosis in rat tissues. Lipids Health Dis 14: 13

36. Bhattaram VA, Cercefe M, Cohlest C, Vest M, Deundo FH (2002) Pharmacokinetics bioavailability herbal medicinal products. Phytomedicine 9(3): 1-33.

37. Airaodion AI, Ogbuagu U, Ogbuagu EO, Airaodion EO, Agunbiade AP, et al. (2019) Investigation of aqueous extract of Zingiber officinale root potential in the prevention of peptic ulcer in albino rats. International Journal of Research and Innovation in Applied Science 4(2): 64-67.

38. Airaodion AI, Obajimi O0, Ezebuiro CN, Ogbuagu U, Agunbiade AP, et al. (2019) Prophylactic efficacy of aqueous extract of Curcuma longa against indomethacin-induced ulcer. International Journal of Research 6(1): 87-91.

39. Airaodion AI, Olayeri IM, Ewa AO, Ogbuagu EO, Ogbuagu U, et al. (2019) Evaluation of Moringa oleifera leaf potential in the prevention of peptic ulcer in wistar rats. International Journal of Research 6(2): 579-584.

40. Saravanan R, Pari L (2005) Antihyperlipidemic and antiperoxidative effect of diasulin, a polyherbal formulation in alloxan induced hyperglycemic rats. BMC Complement Alternative Med 22(5): 14.

41. Airaodion AI, Adekale OA, Airaodion EO, Ogbuagu EO, et al. (2019) Efficacy of Combined crude Extract of Curcuma longa and Moringa oleifera in the Prevention of Peptic Ulcer in Albino Rats. Asian Journal of Research in Medical and Pharmaceutical Sciences 7(2): 1-8.

42. Shoback DG, Gardner D (2011) “Chapter 17”. Greenspan’s Basic \& Clinical Endocrinology ( $9^{\text {th }}$ edn) New York: McGraw-Hill Medical.

43. Saliu JA, Oboh G, Schetinger MR, Stefanello N, Rocha JBT (2015) Antidiabetic Potentials of Jute Leaf (Talinum triangulare) On Type-2 Diabetic Rats. Journal of Emerging Trends in Engineering and Applied Sciences (JETEAS) 6(7): 223- 230

44. Srinivasan K, Viswanad B, Asrat L, Kaul CL, Ramarao P (2005) Combination of high-fat diet-fed and low-dose streptozotocin-treated rat: a model for type 2 diabetes and pharmacological screening. Pharmacological Research 52(4): 313-320.

45. Allen RR, Carson LA, Kwik-Uribe C, Evans E, Erdman JW (2008) Daily consumption of a dark chocolate containing flavanols and added sterol esters affects cardiovascular risk factors in normotensive population with elevated cholesterol. J Nutr 138(4): 725-731.

46. Greene CM, Zern TL, Wood RJ, Shrestha S, Fernandez ML, et al. (2005) Maintenance of the LDL-cholesterol: HDL-cholesterol ratio in an elderly population given a dietary cholesterol challenge. J Nutr 135(12): 27932798.

47. Perona JS, Covas MI, Fito M, Cabello-Moruno R, Aros F, et al. (2010) Reduction in systemic and VLDL triacylglycerol concentration after a 3-month Mediterraneanstyle diet in high-cardiovascular-risk subjects. J Nutr Biochem 21(9): 892-898.

48. Gordon DJ, Rifkind BM (1989) High-density lipoprotein: The clinical implications of recent studies. New England Journal of Medicine 321(19): 1311-1316.

49. Sviridiv D (1999) Intracellular cholesterol trafficking. Histology and Histopathology 14: 305-319. 
50. Navab M, Berliner JA, Watson AD, Hama SY, Territo MC, et al. (1994) The Yin and Yang of oxidation in the development of the fatty streak. A review based on the George Lyman Duff Memorial Lecture. Arterioscler Thromb Vasc Biol 16(7): 831-842.

51. Oram JF, Lawn RM (2001) ABCA1: The gatekeeper for eliminating excess tissue cholesterol. J Lipid Res 42(8): 1173-1179.

52. Law MR (1999) Lowering heart disease risk with cholesterol reduction: Evidence from observational studies and clinical trials. European Heart Journal 1: S3-S8.
53. Stein 0, Stein Y (1999) Atheroprotective mechanisms of HDL. Atherosclerosis 144(2): 285-301.

54. Das DK (2003) Cardio protection with high density lipoproteins. Fact or friction? Circulation Research 92: 258-260.

55. Cromwell WC, Otvos JD (2004) Low Density Lipoprotein Particle Number and Risk for Cardiovascular Disease. Curr Atheroscler Rep 6(8): 381387.

56. Castelli L (1984) Epidemiology of coronary heart disease. Am J Med 76:4-12. 